\title{
Lung Collagen Heterogeneity
}

\author{
SYNTHESIS OF TYPE I AND TYPE III COLLAGEN \\ BY RABBIT AND HUMAN LUNG CELLS IN CULTURE
}

\author{
Allan J. Hance, Kathry Bradley, and Ronald G. Crystal \\ From the Section on Pulmonary Biochemistry, National Heart and Lung \\ Institute, Bethesda, Maryland 20014
}

\begin{abstract}
A B STRACT The fetal and adult lung have a constant level of collagen synthesis that represents $4-5 \%$ of the total amino acids incorporated into lung protein. Prior studies have demonstrated that this collagen is not homogeneous but rather is composed of at least two collagen types, I and II, each localized to specific lung structures. Although it is known that explants of rabbit lung parenchyma and blood vessels synthesize type I collagen and that rabbit lung tracheobronchial tree synthesizes type II collagen, it has been suggested that other collagen types are present in lung. It is not known which cells are responsible for the synthesis of any lung collagen type. To approach the problem of additional lung collagen heterogeneity and the identification of the cells responsible for lung collagen synthesis, techniques were developed to examine collagen synthesized by lung cells in culture.
\end{abstract}

$10-15 \%$ of the proteins synthesized by confluent cultures of rabbit lung cells and fetal human lung fibroblasts are collagen. Separation and purification of this collagen by ion-exchange chromatography and cyanogen bromide $(\mathrm{CNBr})$ peptide mapping techniques indicate that collagen secreted by these cells is composed of two collagen types, I and III. The $\mathrm{CNBr}$ peptides of type I collagen secreted by these cells are identical to the $\mathrm{CNBr}$ peptides of type I collagen synthesized by lung parenchyma and blood vessels. The peptides of type III collagen secreted by these cells are identical to fetal skin type III collagen $\mathrm{CNBr}$ peptides.

The existence of 40 cell types and the insolubility of lung collagen increase the complexity of identifying the types of collagen in lung and the cells responsible for the synthesis of each type. The techniques described here should eventually lead to a complete description of

Received for publication 30 December 1974 and in revised form 5 September 1975. the synthesis and composition of lung collagen, thus providing a probe to understand the role of collagen in lung development and structure in health and disease.

\section{INTRODUCTION}

Lung collagen has been assigned a prominent role in the differentiation, development, structure, and mechanical properties of the lung and in the pathogenesis of a wide spectrum of lung diseases, including fibrotic lung disorders (1). Collagen is the most abundant protein in lung, composing about $20 \%$ of the dry weight of the adult human lung (2-5). This collagen is distributed throughout the lung, including the tracheobronchial tree, blood vessels, and the alveolar interstitium. Both the fetal human lung and the adult human lung have a constant level of collagen synthesis that represents $4-5 \%$ of the total amino acids incorporated into protein $(2,6)$. This collagen is not homogeneous but rather is composed of at least two different collagen types. Each collagen type contains $\alpha$-chain subunits with unique and characteristic amino acid sequences. Previous studies have demonstrated that peripheral lung tissue and pulmonary vascular tissue synthesize type I collagen (chain composition $\left.[\alpha 1(\mathrm{I})]_{2} \alpha 2\right)$. Trachea and bronchial tree synthesize type II collagen (chain composition $[\alpha 1(\mathrm{II})]_{3}$ ). The cyanogen bromide $(\mathrm{CNBr})^{1}$ peptides of rabbit lung $\alpha 1$ (I)-, $\alpha 2$-, and $\alpha 1$ (II)-chains have been characterized and demonstrated to be similar to, if not identical with, the $\mathrm{CNBr}$ peptides of the same collagen chains found in other collagen containing tissues ( 7 ).

It has been suggested, but not proven, that other types of collagen (e.g., type III as in fetal skin [8-13] and

${ }^{1}$ Abbreviations used in this paper: CM, carboxymethyl; $\mathrm{CNBr}$, cyanogen bromide; DEAE, diethylaminoethyl; SDS, sodium dodecyl sulfate. 
type IV as in renal glomerular membrane [14]) may exist in lung $(6,13,14)$. Further definition of the collagen in lung, however, has been hampered by the marked structural complexity of lung and the extreme insolubility of collagen in this organ.

In no case have the cells responsible for the synthesis of the individual collagen types in lung been identified. The recent suggestion that cells from human (15) and calf skin (16) synthesize type I and type III collagen has led to the present investigation, which demonstrates: (a) that cultured cells derived from newborn rabbit lung having the morphologic characteristics of fibroblasts synthesize type I and type III collagen and $(b)$ a defined fetal human lung fibroblast (WI-38) synthesizes both type I and type III collagen. In addition, the large quantities of type III collagen synthesized and secreted by rabbit lung cells in culture have enabled us to carefully map the $\left[{ }^{3} \mathrm{H}\right]$ proline-labeled $\mathrm{CNBr}$ peptides of this insoluble collagen type. Comparison of these maps to the $\left[{ }^{3} \mathrm{H}\right]$ proline-labeled $\mathrm{CNBr}$ peptides of lung types I and II collagen and to unlabeled $\mathrm{CNBr}$ peptides of type III collagen from other species and organs should prove valuable in correlating lung collagen types with lung structure and function in lung development and in lung disorders.

\section{METHODS}

Newborn rabbit lung cell culture. Lungs were excised from two newborn rabbits (B and H Rabbitry, Rockville, Md.), and cells were dispersed by gentle agitation of lungs in $10 \mathrm{ml}$ of $0.25 \%$ trypsin (North American Biologicals, Inc., Rockville, Md.) for $20 \mathrm{~min}$. This procedure was repeated three times; after each period, dissociated cells were transferred into an equal volume of Ham's F-12 medium (Grand Island Biological Co., Grand Island, N. Y.) containing $10 \%$ fetal calf serum (Grand Island Biological Co.). Dissociated cells were then pooled, filtered through four layers of sterile cheese cloth, and pelleted at $600 \mathrm{~g}$ for 10 min. Cells were resuspended in Ham's F-12 medium containing $10 \%$ fetal calf serum and counted and then seeded at a density of $10^{7}$ cells/flask in $15 \mathrm{ml}$ of medium in $250-\mathrm{ml}$ tissue culture flasks (Cooke Laboratory Products Div., Dynatech Laboratories Inc., Alexandria, Va.).

Cultures were grown to confluency and subcultivated with a $1: 3$ division by using $15 \mathrm{ml} /$ flask of Dulbecco-Vogt modified Eagle's medium (NIH Media Unit) containing 10\% fetal calf serum, $100 \mathrm{U} / \mathrm{ml}$ penicillin $\mathrm{G}$, and $100 \mu \mathrm{g} / \mathrm{ml}$ streptomycin (Difco Laboratories, Detroit, Mich.).

By the third passage, the newborn rabbit lung cells had the morphologic characteristics of fibroblasts by phase microscopy. Electron microscopy of a pellet of these cells and en face sections of the tissue culture plate also had the characteristics of fibroblasts. These cells had an oval nucleus with multiple nucleoli and long, extended cytoplasmic processes containing large amounts of rough endoplasmic reticulum. There were no characteristics of other lung cells, such as lamellar inclusion bodies, microvilli, or cilia.

Labeling was performed only on cultures that had reached confluency for 2-3 days. Cultures in third passage were labeled by washing confluent flasks with $10 \mathrm{ml}$ of phos- phate-buffered saline, $\mathrm{pH} 7.4$, and then incubating cells at $37^{\circ} \mathrm{C}$ for $24 \mathrm{~h}$ in $10 \mathrm{ml}$ of Dulbecco-Vogt modified Eagle's medium containing $0.3 \mathrm{mM}$ ascorbic acid (Fisher Scientific Company, Pittsburgh, $\mathrm{Pa}$.), $0.5 \mathrm{mM} \beta$-aminopropionitrile (Calbiochem, San Diego, Calif), $100 \mu \mathrm{g} / \mathrm{ml}$ streptomycin, $100 \mathrm{U} / \mathrm{ml}$ penicillin, and $750 \mu \mathrm{Ci} /$ flask of $\left[5^{-3} \mathrm{H}\right]$ proline $(32$ $\mathrm{Ci} / \mathrm{mmol}$, Schwarz/Mann Div., Becton, Dickinson \& Co., Orangeburg, N. Y.).

WI-38 human lung fibroblast culture. WI-38 fibroblasts, a well documented diploid line derived from human fetal lung, were obtained from the American Type Culture Association in 17th passage. Cultures were grown to confluency in Dulbecco-Vogt modified Eagle's medium containing $10 \%$ fetal calf serum, $100 \mathrm{U} / \mathrm{ml}$ penicillin $\mathrm{G}$, and $100 \mu \mathrm{g} / \mathrm{ml}$ streptomycin. Cells were subcultivated 6-8 times by using a $1: 3$ division as described for newborn lung cells.

WI-38 fibroblasts were labeled in the 24th and 26th passage for $24 \mathrm{~h}$ as described for newborn rabbit lung cells except that $100 \mu \mathrm{Ci} /$ flask of $\left[5-{ }^{8} \mathrm{H}\right]$ proline $(32 \mathrm{Ci} / \mathrm{mmol})$ was used.

Separation of collagen types from culture medium by diethylaminoethyl (DEAE)-chromatography. Cell culture medium was dialyzed against $10 \mathrm{mM}$ Tris- $\mathrm{HCl}(\mathrm{pH} 7.4)$ containing $2 \mathrm{M}$ urea at $4^{\circ} \mathrm{C}$, centrifuged at $5,000 \mathrm{~g}$ for 10 min, and chromatographed at $4^{\circ} \mathrm{C}$ on DEAE-cellulose (DE 52, Whatman) (17). Fractions comprising each peak were pooled, dialyzed against $0.1 \mathrm{~N}$ acetic acid, lyophilized, and stored at $-20^{\circ} \mathrm{C}$.

Separation and purification of $\alpha$-chains by carboxymethyl $(C M)$-cellulose chromatography. In some cases, component $\alpha$-chains were separated by dialysis of material from individual DEAE-cellulose peaks against $0.02 \mathrm{M}$ sodium acetate ( $\mathrm{pH} 4.8$ ) containing $1 \mathrm{M}$ urea, after which samples were denatured and chromatographed on CM-cellulose as previously described (7). Peaks were pooled, dialyzed against $0.1 \mathrm{~N}$ acetic acid and lyophilized.

Sodium dodecyl sulfate (SDS)-acrylamide gel electrophoresis of collagen chains. Material from peaks separated by DEA.E-cellulose chromatography or $\alpha$-chains isolated by CM-cellulose chromatography were denatured by incubation at $37^{\circ} \mathrm{C}$ overnight in $1 \% \mathrm{SDS}$ and $0.1 \mathrm{M}$ phosphate buffer ( $\mathrm{pH} 7.4$ ) with or without reduction with $1 \% \beta$ mercaptoethanol (Calbiochem) and run on $5 \%$ acrylamide/ $0.17 \%$ methylbisacrylamide SDS gels at $12 \mathrm{~mA} / \mathrm{gel}$ for $6 \mathrm{~h}$. Methods used for polymerization and counting of gels have previously been described (2).

Collagenase digestion of collagen chains. Duplicate 2-ml samples from each peak separated by DEAE-cellulose chromatography were dialyzed against $2.5 \mathrm{mM} N$-ethylmaleimide (Sigma Chemical Co., St. Louis, Mo.), $1 \mathrm{mM} \mathrm{CaCl}$, and $25 \mathrm{mM}$ Tris- $\mathrm{HCl}\left(\mathrm{pH} \mathrm{7.4)}\right.$ and then incubated at $37^{\circ} \mathrm{C}$ for $3 \mathrm{~h}$ with or without $200 \mu \mathrm{l}$ of purified Clostridial collagenase (Advanced Biofactures, Lynbrook, N. Y.; form III) (2). Samples were subsequently dialyzed overnight against $50 \mathrm{mM}$ Tris- $\mathrm{HCl}$ ( $\mathrm{pH} 7.4$ ) containing $0.2 \mathrm{~N} \mathrm{NaCl}$ and aliquots run on $5 \%$ SDS-acrylamide gels as described above.

$\mathrm{CNBr}$ cleavage and peptide mapping. Purified $\alpha$-chains and material from individual peaks separated by DEAEcellulose chromatography were cleaved by $\mathrm{CNBr}$ as previously described (7). Reagent and formic acid were removed by rotary evaporation at $25^{\circ} \mathrm{C}$. $\mathrm{CNBr}$ peptides were separated by chromatography on a $1.5 \times 5-\mathrm{cm}$ column of CM-cellulose equilibrated with $0.02 \mathrm{M}$ sodium citrate $(\mathrm{pH}$ 3.8) containing $0.01 \mathrm{M} \mathrm{NaCl}$ and eluted with a linear $\mathrm{NaCl}$ gradient (0.01-0.16 M, $500 \mathrm{ml}$ total) (12). Fractions from each major peak were desalted on a Biogel P-2 (Bio-Rad 
Laboratories, Richmond, Calif.) column with $0.1 \mathrm{~N}$ acetic acid as elutant and lyophilized.

Aliquots of the original peptide mixture and individual $\mathrm{CNBr}$ peptides separated by CM-cellulose chromatography were examined on SDS-acrylamide gels by using $7.5 \%$ acrylamide/ $0.27 \%$ methylbisacrylamide gels (peptide pools and individual peptides) or $10 \%$ acrylamide $/ 0.27 \%$ methylbisacrylamide gels (individual peptides only) electrophoresed at $8 \mathrm{~mA} /$ gel for $6 \mathrm{~h}$.

Limited digestion of collagenous protein with pepsin. Limited pepsin digestion was performed by suspending material in peaks separated by DEAE-cellulose chromatography in $0.5 \mathrm{~N}$ acetic acid containing $10 \mu \mathrm{g} / \mathrm{ml}$ pepsin (Worthington Biochemical Corp., Freehold, N. J.) and incubating at $15^{\circ} \mathrm{C}$ for $4 \mathrm{~h}$ (18). The digestion was stopped by chilling at $4^{\circ} \mathrm{C}$ and neutralizing to $\mathrm{pH} 7.4$ with Tris base. Samples were then dialyzed against $0.1 \mathrm{~N}$ acetic acid and lyophilized.

SDS-acrylamide gel electrophoresis, separation and purification of $\alpha$-chains, and $\mathrm{CNBr}$ cleavage and peptide mapping were performed on pepsin-digested collagen as described above.

Isolation of carrier $\alpha 1(I)$ - and $\alpha 2$-chains and $\alpha 1(I I I)-$ chains. Extraction of type I collagen from lathrytic rabbit skin and isolation and purification of component $\alpha \mathrm{l}(\mathrm{I})$ and $\alpha 2$-chains has been described (2). Extraction of type III collagen from lathrytic rabbit skin was done identically to that described by Chung, Miller, and Keele $(8,9)$ for human type III except that increased yields of rabbit skin type III were obtained by solubilizing the post-pepsindigested, lyophilized collagen in $0.2 \mathrm{M} \mathrm{NaCl}-50 \mathrm{mM}$ Tris$\mathrm{HCl}, \mathrm{pH} \mathrm{7.4,} \mathrm{and} \mathrm{precipitating} \mathrm{the} \mathrm{type} \mathrm{III} \mathrm{collagen} \mathrm{with}$ $1.4 \mathrm{M} \mathrm{NaCl}$.

Quantitation of hydroxyproline to proline ratios. Peaks I and III from DEAE-cellulose were subjected to limited digestion with pepsin as described above. The resulting ${ }^{14} \mathrm{C}$ labeled tropocollagens were hydrolyzed in $6 \mathrm{~N} \mathrm{HCl}$ for $24 \mathrm{~h}$ and the ratio of $\left[{ }^{14} \mathrm{C}\right]$ hydroxyproline to $\left[{ }^{14} \mathrm{C}\right]$ proline in each collagen type determined as previously described (2).

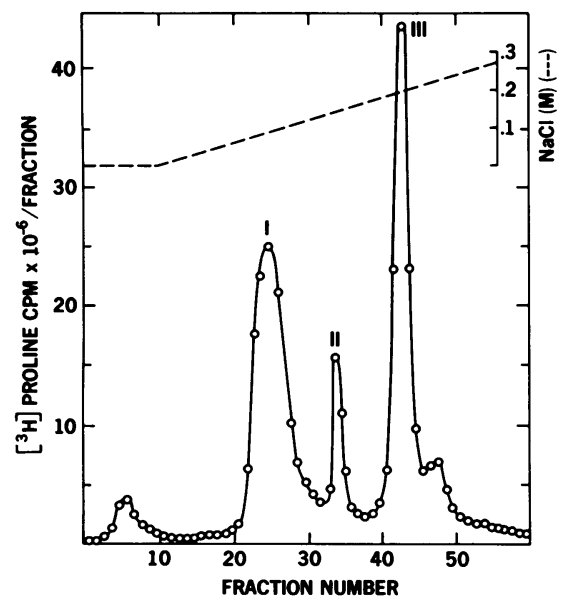

Figure 1 DEAE-cellulose chromatography of medium from newborn rabbit lung cells incubated for $24 \mathrm{~h}$ with medium containing $\left[{ }^{3} \mathrm{H}\right]$ proline. Before chromatography medium was dialyzed against $10 \mathrm{mM}$ Tris- $\mathrm{HCl}(\mathrm{pH}$ 7.4) containing $2 \mathrm{M}$ urea. $10-\mathrm{ml}$ fractions were collected and aliquots counted in Aquasol with an efficiency of $30 \%$. $\mathrm{cpm} /$ fraction (O-O) and molarity of $\mathrm{NaCl}$ gradient used to elute the column (----) are shown.

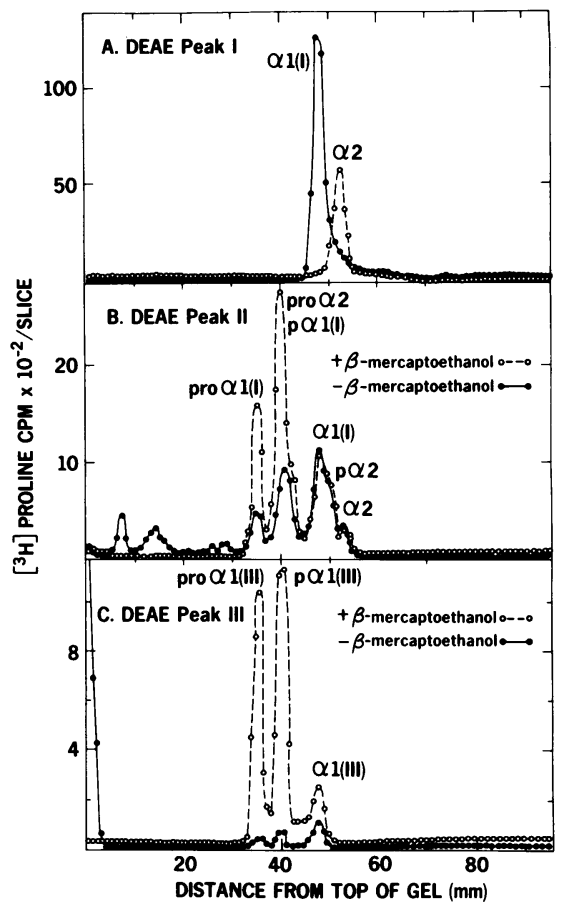

FIGURE 2 SDS-acrylamide gel electrophoresis of material in peaks separated by DEAE-cellulose chromatography. (A) $\alpha 1$ (I)-Chains (@- ) and $\alpha 2$-chains (O-- O) present in peak I were separated by CM-cellulose chromatography before electrophoresis. (B) Material present in peak II before ( $-\bullet)$ and after $(\mathrm{O}-\mathrm{O})$ reduction with $\beta$-mercaptoethanol. (C) Material present in peak III before $(\mathrm{O}-\mathrm{O})$ and after $(\bullet-\cdots)$ reduction with $\beta$ mercaptoethanol. Gels were electrophoresed at $12 \mathrm{~mA} / \mathrm{gel}$ for $8 \mathrm{~h}$ in parallel.

\section{RESULTS}

$D E A E$-cellulose chromatography of rabbit lung cell medium. After dialysis of medium from cultured rabbit lung cells in preparation for DEAE-cellulose chromatography, greater than $90 \%$ of $\left[{ }^{3} \mathrm{H}\right]$ proline-labeled protein remained in solution. Subsequent chromatography on DEAE-cellulose separated the $\left[{ }^{3} \mathrm{H}\right]$ proline-labeled proteins into three distinct peaks, hereafter referred to as "DEAE peaks I, II, and III" (Fig. 1). Studies with skin fibroblasts have indicated that type I tropocollagen elutes in the vicinity of peak I, precursor forms of type I collagen elute in peak II, and precursor forms of type III collagen elute in peak III $(15,17)$. The relative number of counts in peaks II and III was variable between different cultures. Cultures in higher passage contained relatively more counts in peak II (data not shown).

$D E A E$ peak I. Chromatography on CM-cellulose of material eluting in peak I gave two peaks corresponding to $\alpha 1$ - and $\alpha 2$-chains in the characteristic ratio (2:1) for type I collagen (data not shown). No radioactivity 


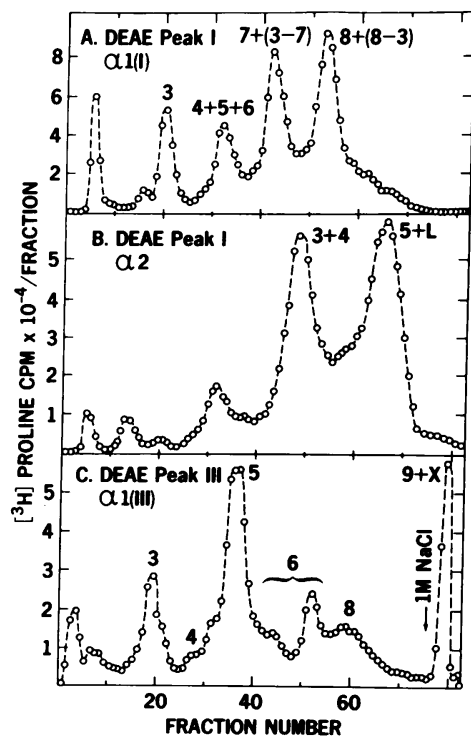

FIGURE 3 CM-cellulose chromatography of $\mathrm{CNBr}$ peptides of collagen chains synthesized by newborn rabbit lung cells. (A) $\alpha 1$ (I)-Chains from DEAE peak I, separated and purified by CM-cellulose chromatography before $\mathrm{CNBr}$ cleavage. (B) $\alpha 2$-Chains from DEAE peak I, separated and purified by $\mathrm{CM}$-cellulose chromatography before $\mathrm{CNBr}$ cleavage. (C) $\alpha 1$ (III) procollagen chains present in peak III.

Columns $\mathrm{A}-\mathrm{C}$ were run in an identical fashion, except that column $\mathrm{C}$ was washed with starting buffer containing $1 \mathrm{M} \mathrm{NaCl}$. 5-ml fractions were collected and aliquots counted in Aquasol. Rabbit skin $\alpha 1$ (I) $\mathrm{CNBr}$ peptides were used as carrier in $\mathrm{A}$ and $\mathrm{C}$. Rabbit skin $\alpha 2 \mathrm{CNBr}$ peptides were used as carrier in B. Profiles from carrier $\alpha 1$ (I) and $\alpha 2 \mathrm{CNBr}$ peptides (not shown) were identical to the $\alpha 1(\mathrm{I})$ - and $\alpha 2$-chains synthesized by the cells in culture. Identification of the $\mathrm{CNBr}$ peptides was made by analogy to known $\alpha 1$ (I), $\alpha 2$, and $\alpha 1$ (III) peptides (see Results), as well as by determination of molecular weights of peptides in individual peaks by SDS-acrylamide gel electrophoresis (Fig. 5). The $1 \mathrm{M} \mathrm{NaCl}$ wash peak in $\mathrm{C}$, contained $\alpha 1$ (III) CB9 and additional unidentified material (X).

was found in the region where $[\alpha 1 \text { (III) }]_{3}$ has been described to elute from this column (8), $\alpha 1$ - and $\alpha 2$-chains separated by CM-cellulose chromatography ran as single sharp peaks on SDS-acrylamide gels in a position characteristic of $\alpha 1(\mathrm{I})$ - and $\alpha 2$-chains with a molecular weight of 95-100,000 daltons (Fig. 2A). Incubation of material in peak I with collagenase before electrophoresis eliminated over $95 \%$ of counts, which otherwise ran as $\alpha$-chains, indicating that essentially all of the $\left[{ }^{3} \mathrm{H}\right]$ proline incorporated into protein identifiable on $5 \%$ SDS-acrylamide gels is incorporated into predominantly collagenous regions (data not shown). The identity of these chains was definitively established as $\alpha 1$ (I)- and $\alpha 2$-chains by analysis of the peptide fragments produced by $\mathrm{CNBr}$ cleavage. The $\mathrm{CNBr}$ peptides produced from the $\alpha 1$ - and $\alpha 2$-chains co-chromatographed on CM-cel- lulose with those from $\alpha 1(\mathrm{I})$ - and $\alpha 2$ carrier chains, respectively, and the patterns produced were identical to the $\mathrm{CNBr}$ peptide patterns previously described from peripheral lung $\alpha 1$ (I) - and $\alpha 2$-chains (Figs. 3A and B). Similarly, the pattern of the $\mathrm{CNBr}$ peptides separated on the basis of molecular weight by using SDS-acrylamide gel electrophoresis were similar to patterns previously reported for $\alpha 1$ (I)- and $\alpha 2$-chains $(1,7)$ (Figs. $4 \mathrm{~A}$ and $\mathrm{B}$ ).

$D E A E$ peak II. When aliquots of peak II were reduced and denatured and subsequently electrophoresed

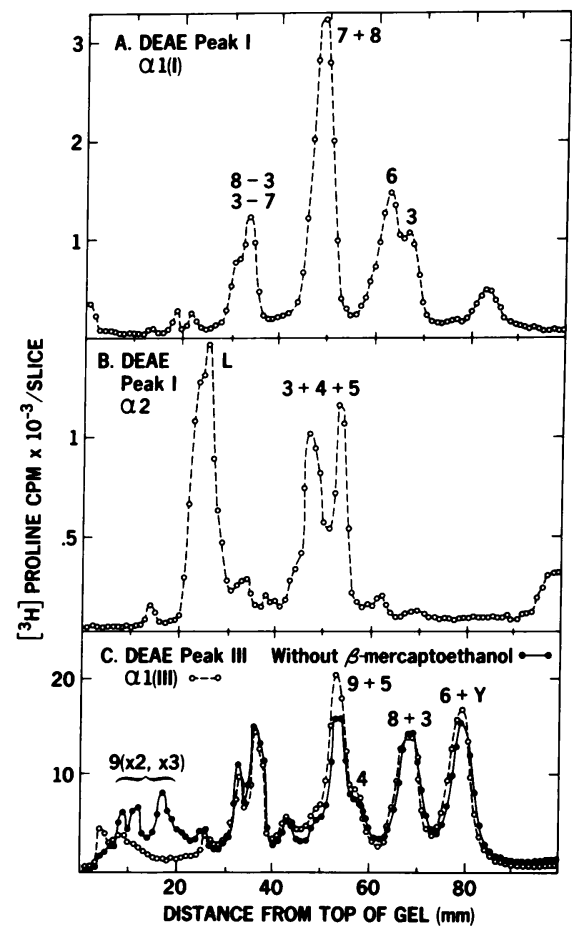

Figure 4 SDS-acrylamide gels of $\mathrm{CNBr}$ peptides of collagen chains synthesized by newborn rabbit lung cells. The peptides placed on gels A-C were identical to those chromatographed on CM-cellulose (Figs. 3A-C). (A) $\alpha 1(\mathrm{I})-$ Chains present in DEAE peak I; (B) $\alpha 2$ present in DEAE peak I; and (C) $\alpha 1$ (III) procollagen present in DEAE peak III before (-๑) and after $(\mathrm{O}-\mathrm{O}-\mathrm{O})$ reduction with $\beta$-mercaptoethanol. All gels were electrophoresed at $8 \mathrm{~mA} /$ gel for $6 \mathrm{~h}$ in parallel. Identification of $\mathrm{CNBr}$ peptides was made by isolating major peptides from CMcellulose chromatography and electrophoresing them on individual gels (see Fig. 6 and Results). $\mathrm{CNBr}$ peptides of rabbit skin $\alpha 1(\mathrm{I})$ - and $\alpha 2$-chains were run in parallel gels and demonstrated identical patterns to $\mathrm{A}$ and $\mathrm{B}$, respectively (data not shown). In $B$, the $\alpha 2$ peptide labeled " $L$ " was identical to that found in rabbit lung parenchyma and probably represents an uncleaved (or absent) methionine in a large peptide of this chain (7). In C, the $\alpha \mathrm{l}$ (III) peptide labeled " $6+Y$ " contains $\alpha 1$ (III)CB6 plus unknown material unaccounted by known $\alpha 1$ (III) $\mathrm{CNBr}$ peptides. Similar molecular weight material eluted on CM-cellulose between fractions 40-60 (See Fig. $3 \mathrm{C}$ and Results). 
on $5 \%$ SDS-acrylamide gels, a small amount of material ran in the molecular weight range characteristic of $\alpha 1$ - and $\alpha 2$-chains. The bulk of the $\left[{ }^{3} \mathrm{H}\right]$ proline-labeled material was in several larger proteins with molecular weight between 110,000 and 140,000 daltons (Fig. 2B). Others have shown that these larger proteins are intact procollagen chains (proa1(I) and proa2) and chains intermediate in the conversion of procollagen to collagen $(\mathrm{p} \alpha 1(\mathrm{I})$ and $\mathrm{p} \alpha 2)(15,18,19))^{2}$ Without reduction, the recovery of $\alpha 1-$ and $\alpha 2$-chains was unchanged, but most of the larger precursor forms either ran in a position indicating a molecular weight in excess of 200,000 or failed to penetrate the gel, suggesting these precursor forms were initially disulfide linked (Fig. 2B). The profile on SDS-acrylamide gels of these precursors present in the culture medium are similar to those demonstrated in human skin fibroblast media by Goldberg and Sherr (18). In the present study, no steps were taken to inhibit proteolysis during dialysis before electrophoresis, and since nonspecific degradation of the pro region is known to occur under these conditions, this probably explains our finding that relatively more material was present in the region characteristic of $\alpha 1$ - and $\alpha 2$-chains.

Collagenase digestion of peak II before denaturation, reduction, and electrophoresis eliminated greater than $90 \%$ of counts from the gel, indicating that all peaks contained labeled protein with predominantly collagenous regions (data not shown). The pro regions of these chains are not extensively digested by collagenase, but they contain little proline and would therefore not be expected to contribute label to these gels.

If limited pepsin digestion of the material in DEAE peak II was performed before SDS-acrylamide gel electrophoresis, all radioactivity recovered was in the positions characteristic of $\alpha 1$ (I)- and $\alpha 2$-chains, and these peaks were present in a $2: 1$ ratio (data not shown). Such pepsin treatment is known to digest the pro region from collagen precursors, but leave the bulk of the triple helical tropocollagen intact (18). No further experiments were performed to characterize the precursorproduct relationship of these chains.

$D E A E$ peak III. When material from peak III was reduced, denatured, and run on SDS-acrylamide gels, three distinct peaks corresponding to molecular weights $130-140,000,110-120,000$, and $95-100,000$ daltons were found (Fig. 2C). In human skin fibroblasts, peaks similar to those described here with molecular weights 140 ,000 [pro $\alpha 1$ (III)], 120,000 [p 1 (III)], and 100,000 $[\alpha 1$ (III)] have been found in the larger peaks identified

\footnotetext{
${ }^{2}$ To avoid confusion in the literature, we have adopted the nomenclature "pro $\alpha$ " and "p $\alpha$ " for these precursors as used by Lichtenstein et al. (15) and Bornstein (20).
}

as precursor forms of $\alpha 1$ (III). If material was electrophoresed before reduction, most failed to penetrate the gel more than 1-2 $\mathrm{mm}$, indicating these precursors were aggregated through disulfide bonds (Fig. 2C).

When material from peak III was subjected to limited pepsin digestion and subsequently reduced, all radioactivity recovered was in a single peak characteristic of $\alpha 1$-chains with molecular weight of $95-100,000$ daltons (data not shown). Prior collagenase digestion of material in peak III eliminated greater than $95 \%$ of counts otherwise recovered in the gel. These data are also consistent with material in peak III being predominantly collagenous protein, but in addition containing a "pro" region characteristic of precursor forms susceptible to limited pepsin digestion.

When material in peak III was subjected to limited pepsin digestion, the resulting material had a ratio of $\left[{ }^{14} \mathrm{C}\right]$ hydroxyproline to $\left[{ }^{14} \mathrm{C}\right]$ proline of 1.22 . This is similar to the ratio of hydroxyproline to proline (1.17) found in type III tropocollagen from uterine leiomyoma (8). In comparison, the ratio of $\left[{ }^{14} \mathrm{C}\right]$ hydroxyproline to $\left[{ }^{14} \mathrm{C}\right]-$ proline found in peak I after limited pepsin digestion was 0.87 . This is almost identical to the ratio found in type I tropocollagen isolated from rabbit lung (0.84) (2).

Characterization of $C N B r$ peptides of $\alpha 1$ (III) synthesized by lung cells by $C M$-cellulose chromatography. To prove that the chains present in peak IIII were related to $\alpha 1$ (III) collagen chains, the chains were cleaved with $\mathrm{CNBr}$ and the $\mathrm{CNBr}$ peptides of the collagenous protein of peak III were separated by CM-cellulose chromatography (Fig. 3C). The elution profile is clearly distinguishable from those of the $\alpha 1$ (I)- and $\alpha 2$-chains (Figs. 3A and $\mathrm{B}$ ) and bears striking similarity to that described by Chung et al. (9) for pepsin-digested human skin $\alpha 1$ (III), except that no radioactivity eluted in the position described for $\alpha 1$ (III)CB9, the C-terminal peptide known to contain cysteine residues. When the $\left[{ }^{3} \mathrm{H}\right]-$ proline-labeled proteins in DEAE peak III were treated with limited pepsin digestion identical to that described by Chung et al. (9) to isolate $\alpha 1$ (III) collagen chains from human skin, the $\mathrm{CNBr}$ peptides co-chromatographed on CMC with $\alpha 1$ (III)-chains isolated from pepsin-digested rabbit skin (Fig. 5).

To further demonstrate the analogy between the $\mathrm{CNBr}$ peptides from peak III and those of $\alpha 1$ (III) described by Chung et al. (9) and Epstein (10), molecular weights of the $\mathrm{CNBr}$ peptides present in each peak of the CM-cellulose $\mathrm{CNBr}$ peptide pattern (Fig. 3C) were determined by SDS-acrylamide gel electrophoresis. The results were as follows :

$\alpha 1$ (III) CB3 eluted on CM-cellulose just before $\alpha 1$ (I)$\mathrm{CB} 3$ and its molecular weight by gel electrophoresis was $12-13,000$ (Fig. 6C). 


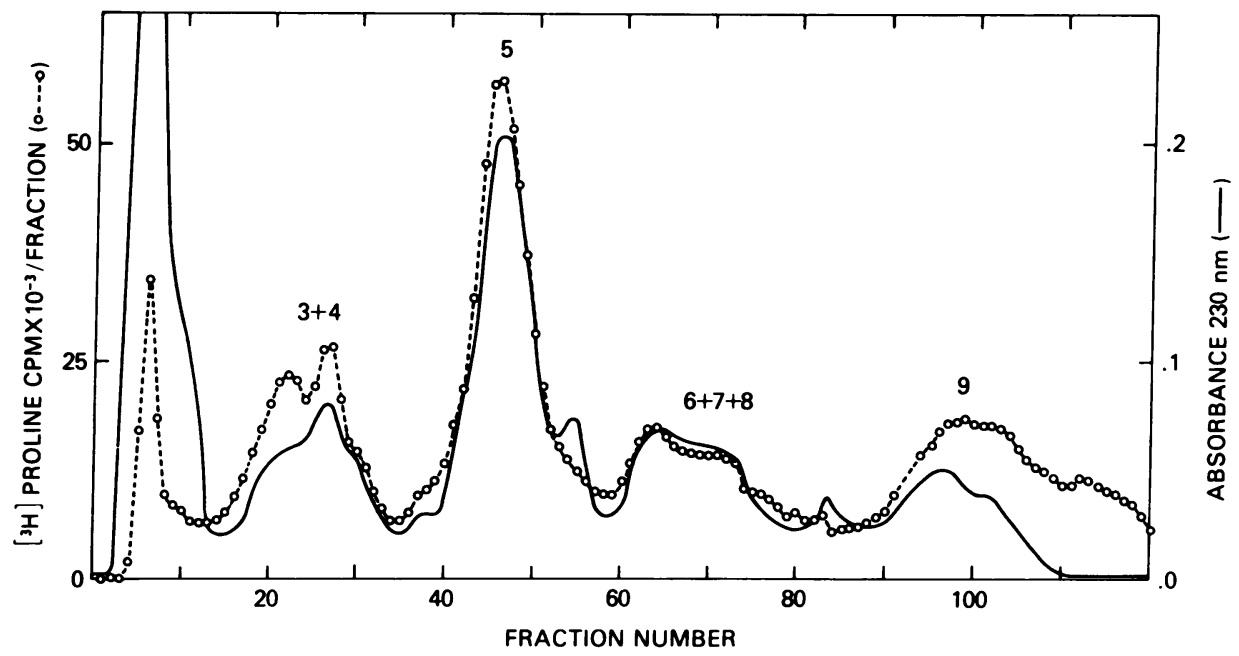

FIGURE 5 CM-cellulose chromatography of $\mathrm{CNBr}$ peptides of type III collagen exposed to limited pepsin digestion before $\mathrm{CNBr}$ cleavage. $\left[{ }^{3} \mathrm{H}\right]$ Proline-labeled type III collagen was isolated from DEAE peak III (Fig. 1) before pepsin exposure and subsequent $\mathrm{CNBr}$ cleavage (O- - O). Rabbit skin type III collagen was isolated and purified as described by Chung et al. (9) before CNBr cleavage (-).

$\alpha 1$ (III)CB4 eluted on CM-cellulose between $\alpha 1$ (I)$\mathrm{CB} 3$ and $\alpha 1(\mathrm{I}) \mathrm{CB} 4+5$ and had a molecular weight of 13,000-13,500 (Fig. 6C).

$\alpha 1$ (III) CB5 eluted on CM-cellulose between $\alpha 1$ (I)$\mathrm{CB} 4+5$ and $\alpha 1$ (I) CB7; its molecular weight by SDSacrylamide gel electrophoresis was approximately 20,000 (Fig. 6D).

$\alpha 1$ (III) CB6 eluted on CM-cellulose just after $\alpha 1$ (I)CB7 and demonstrated a molecular weight of $7-8,000$ (data not shown).

$\alpha 1$ (III) CB7 (molecular weight of 4,000 ) could not be demonstrated by these techniques, presumably because its low content of proline and hydroxyproline (five residues total [9]) would not account for a significant proportion of incorporation of $\left[{ }^{3} \mathrm{H}\right]$ proline.

$\alpha 1$ (III) CB8 eluted on CM-cellulose just after $\alpha 1$ (I)CB8 and had a molecular weight of 12-13,000 (data not shown).

The elution position and molecular weights of $\alpha 1$ (III) CB3, 4, 5, 6, and 8 are almost identical to those described for human skin $\alpha 1$ (III) CNBr peptides (9, 10).

There was no labeled material eluting from the CMcellulose column in the region described by Chung et al. for $\alpha 1$ (III) CB9. This peptide is of particular importance since it is C-terminal and, at least in human skin, con-

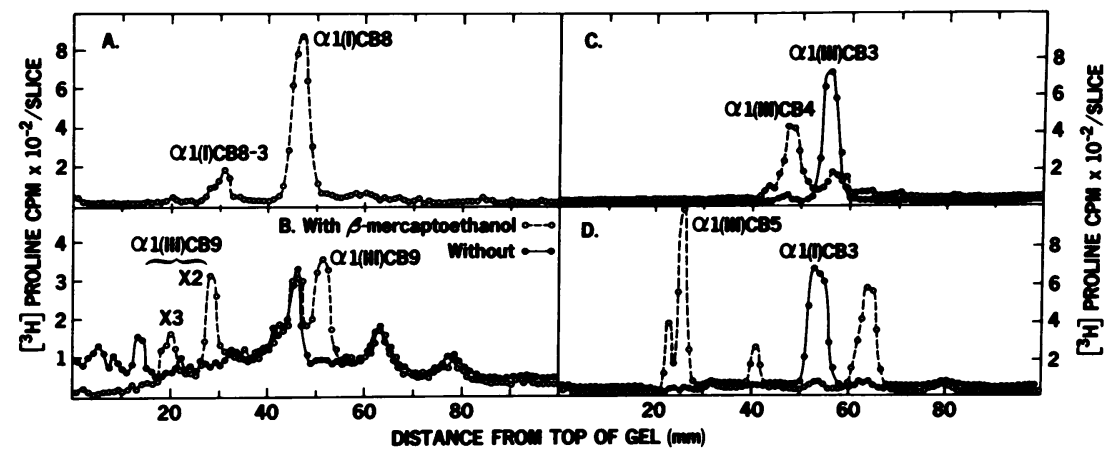

Figure 6 Peak fractions from CM-cellulose chromatography of $\mathrm{CNBr}$ peptides of collagen chains synthesized by newborn rabbit lung cells (Figs. 3A-C) were desalted, lyophilized, and electrophoresed on SDS-acrylamide gels. (A) Figs. 3A-fraction 55; (B) Fig. 3C-fraction 80 before (-— ) and after (O- - - O) reduction with $\beta$-mercaptoethanol ; (C) Fig. 3C-fraction $19(-0)$ and Fig. 3C-fraction $29(\mathrm{O}--\mathrm{O})$; and (D) Fig. 3C-fraction 37 (O- - O ) and Fig. 3A-fraction $21(\bullet-\bullet)$. Gels $\mathrm{A}$ and $\mathrm{B}$ are $7.5 \%$ acylamide and gels $\mathrm{C}$ and D are $10 \%$ acrylamide. All gels were electrophoresed at $8 \mathrm{~mA} / \mathrm{gel}$ for $6 \mathrm{~h}$. 

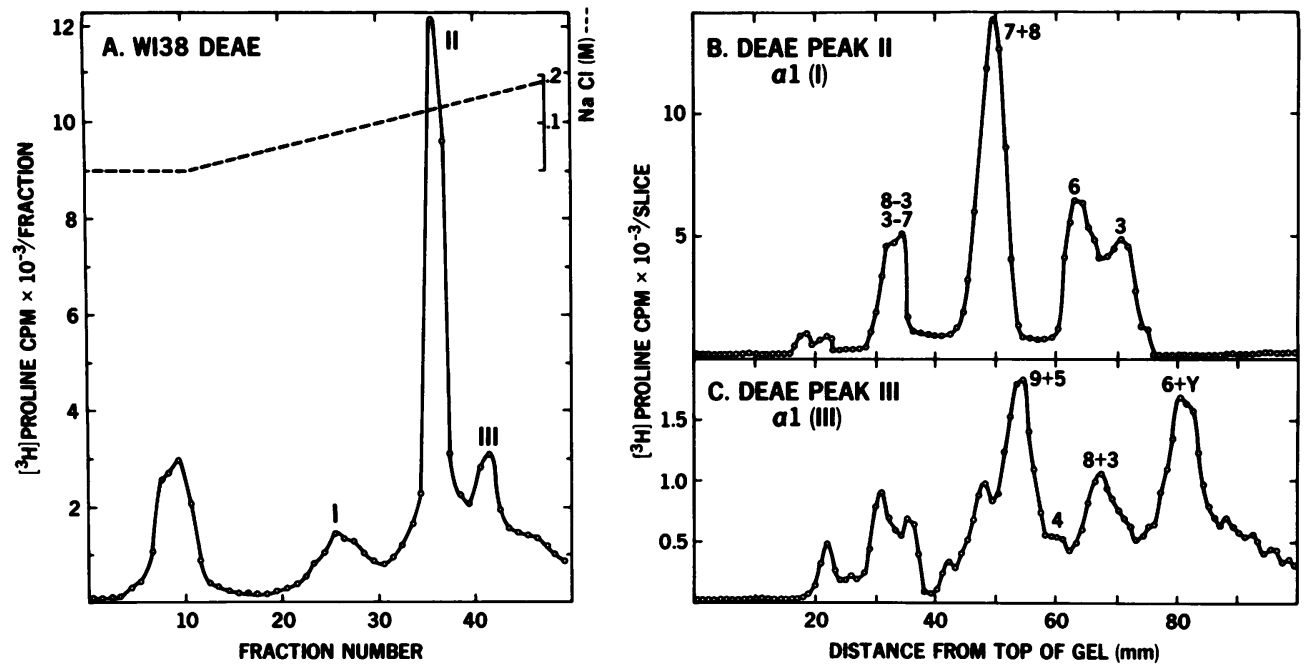

FIGURE 7 (A) DEAE-cellulose chromatography of medium from WI-38 human lung fibroblasts incubated for $24 \mathrm{~h}$ with medium containing $\left[{ }^{3} \mathrm{H}\right]$ proline. Shown are $\mathrm{cpm} /$ fraction $(\mathrm{O}-\mathrm{O})$ and molarity of $\mathrm{NaCl}$ gradient used to elute the column (----). ( $\mathrm{B}$ and $\mathrm{C}$ ) SDS-acrylamide gel electrophoresis of material in peaks separated by DEAE-cellulose chromatography of WI-38 fibroblast medium. (B) $\alpha 1$ (I)-Chains present in peak II were isolated by CM-cellulose chromatography after limited pepsin digestion of DEAE peak II. (C) Material in DEAE peak III after limited pepsin digestion. Gels were electrophoresed at $8 \mathrm{~mA} / \mathrm{gel}$ for $8 \mathrm{~h}$ in parallel.

tains cysteine residues, a very uncommon finding in collagen $\alpha$-chains (9). However, when our CM-cellulose $\mathrm{CNBr}$ peptide column was washed with starting buffer containing $1 \mathrm{M} \mathrm{NaCl}$, additional radioactivity was recovered. When this material was reduced and examined on SDS-acrylamide gels, peptides of molecular weight of $20-21,000,40-42,000$, and 60-65,000 were found (Fig. $6 \mathrm{~B}$ ), corresponding to the $\alpha 1$ (III) CB9 peptide together with $\alpha 1$ (III) CB9 disulfide-linked dimers and trimers. Difficulty in isolating $\alpha 1$ (III) CB9 only in its monomeric form is also described by Chung et al. When the CMcellulose-1 $\mathrm{M} \mathrm{NaCl}$ wash was run on SDS-acrylamide gels without prior reduction, the $\alpha 1$ (III) CB9 peptides were not seen, but radioactivity was found in higher molecular weight regions (including a substantial portion which did not penetrate the gel), indicating peptide $\alpha 1$ (III) CB9 was aggregated through disulfide bonds (Fig. 6B).

A peptide (Fig. 6B, $47 \mathrm{~mm}$ from top of gel) eluting from the CM-cellulose column with $\alpha 1$ (III)CB9 had a molecular weight of 24,000 . This is larger than any reported $\alpha 1$ (III) $\mathrm{CNBr}$ peptide, and it may represent a peptide resulting from incomplete cleavage of methionine residues in lung $\alpha 1$ (III)-chains or, less likely, crosslinked $\alpha 1$ (III) peptides. The molecular weight of this peptide was not influenced by reduction.

Characterization of CNBr peptides of $\alpha 1$ (III) synthesized by lung cells by SDS-acrylamide gel electrophoresis. When the collagen chains from peak III were cleaved with $\mathrm{CNBr}$ and directly separated on the basis of molecular weight by SDS-acrylamide gel electrophoresis without prior CM-cellulose chromatography, most of the peaks were found to correspond to $\alpha 1$ (III) peptides already identified (Fig. $4 \mathrm{C}$ ). Without prior reduction, $\alpha 1$ (III) CB9 was found in aggregated forms with molecular weight greater than 60,000 , but after reduction migrated in the region corresponding to its monomeric molecular weight of $20-21,000$ daltons. Several larger peptides (especially in the $25-35,000$ dalton molecular weight range) probably represent fragments which are products resulting from incomplete cleavage of methionine residues by $\mathrm{CNBr}$. Their position and relative amount were unchanged if peak III was subjected to limited pepsin digestion before $\mathrm{CNBr}$ degradation, indicating they do not represent noncollagenous protein or regions from the pro portion of the collagen chain (data not shown).

The total CNBr peptides of DEAE peak III also gave a peak of radioactivity of molecular weight $8-10,000$ daltons that could not be explained by the presence of $\alpha 1$ (III) CB6 alone (Fig. 4C, peak labeled " $6+Y$ "). We have also noted a peptide(s) of the same molecular weight eluting from CM-cellulose between fractions $40-60$ (Fig. 3C). The etiology of this material is not known.

$D E A E$ chromatography of WI-38 human lung fibroblast medium. Medium from WI-38 human lung fibroblasts was chromatographed on DEAE-cellulose, and 
peaks corresponding to peaks I, II, and III separated from rabbit lung cell medium were seen (Fig. 7A). The relative proportion of peak III to peak II suggested relatively less $\alpha 1$ (III) present in the WI-38 medium.

Peak II: WI-38 fibroblasts. After limited pepsin digestion, material from peak II was chromatographed on CM-cellulose, and two peaks eluting in positions characteristic of $\alpha 1$ (I) - and $\alpha 2$-chains (present in a 2:1 ratio) were identified (data not shown). $\mathrm{CNBr}$ peptides of the $\alpha 1$-chains isolated by CM-cellulose chromatography from pepsin-digested peak II gave a pattern characteristic for $\alpha 1(\mathrm{I})$-chains when separated by SDS-acrylamide gel electrophoresis (Fig. 7B) and CM-cellulose chromatography (data not shown).

Peak III: WI-38 fibroblasts. Material in peak III separated by DEAE chromatography was subjected to limited pepsin digestion and chromatographed on CMcellulose. The majority of radioactivity in peak III eluted just before the $\alpha 2$ region, the characteristic elution position of $[\alpha 1 \text { (III) }]_{3}$ (13) (data not shown).

To conclusively identify the $\alpha$-chain type present in peak III, previously pepsin-digested material was cleaved with $\mathrm{CNBr}$, and the $\mathrm{CNBr}$ peptides were separated by SDS-acrylamide gel electrophoresis (Fig. 7C). The resulting pattern is almost identical to $\alpha 1$ (III)-chains synthesized by rabbit lung cells.

\section{DISCUSSION}

Confluent cultures of both rabbit and human lung cells synthesize three distinct $\alpha$-chains, $\alpha 1(\mathrm{I}), \alpha 2$, and $\alpha 1$ (III), which compose two distinct types of collagen, type I (chain composition $[\alpha 1(\mathrm{I})]_{2} \alpha 2$ ) and type III (chain composition $\left.[\alpha 1(\text { III })]_{3}\right)$. Adult human lung explants synthesize collagen chains which: $(a)$ elute on CM-cellulose in the region described for $\alpha 1$ (III); (b) have a molecular weight of $100-130,000$; and (c) have a hydroxyproline-to-proline ratio of 0.9-1.1 (6). Epstein $(10,13)$ has isolated a single $\mathrm{CNBr}$ peptide from adult human lung which co-chromatographs on CM-cellulose and Sepharose 4B with $\alpha 1$ (III) CB113 (nomenclature of Epstein [10]). These fragmentary data plus the finding of $\alpha 1$ (III)-chains in these cultures suggest, but do not conclusively prove, that lung synthesizes $\alpha 1$ (III)-chains in vivo. As noted by several investigators $(8-10,15), \alpha 1$ (III) .collagen chains are extremely insoluble and difficult to extract intact. Even in adult tissues much richer in collagen than lung (e.g., skin, uterine leiomyoma, aorta), $\alpha 1$ (III)-chains are extracted only after limited proteolysis with pepsin. To this date, we have been unable to extract sufficient quantities of purified intact $\alpha 1$ (III)-chains from adult lung to permit detailed $\mathrm{CNBr}$ peptide analysis such as shown here for the collagen synthesized by lung cell cultures. If, in fact, lung does contain type III collagen, it would make this organ the most heterogeneous of all organs yet studied in regard to collagen composition since types I and II collagen are also present. It is likely that this heterogeneity will be compounded when lung basement membrane (type IV) is clearly demonstrated.

Previous studies have indicated that the $\alpha 1$ (I) - and $\alpha 2$-chains synthesized by lung explant culture were similar to $\alpha 1(\mathrm{I})$ - and $\alpha 2$-chains found elsewhere in the body. Characterization of these chains to the level of the $\mathrm{CNBr}$ peptide revealed no structural differences specific to lung (7). The $\mathrm{CNBr}$ peptides of $\alpha 1$ (I)- and $\alpha 2$-chains synthesized by lung cells in tissue culture are also characteristic of these $\alpha$-chain types, and their separation by $\mathrm{CM}$-cellulose and SDS-acrylamide gel electrophoresis gave patterns similar to those described previously. In addition, most of the $\mathrm{CNBr}$ peptides of the $\alpha 1$ (III)-chain synthesized by lung cells have now been characterized, and their molecular weights and chromatographic properties on CM-cellulose are almost identical to those described for the $\mathrm{CNBr}$ peptides of $\alpha 1$ (III)chains extracted from human skin $(9,10)$. The finding of different chromatographic properties on CM-cellulose of $\alpha 1$ (III)CB9 in our studies is not surprising, since our $\alpha 1$ (III)-chains were intact, whereas the $\alpha 1$ (III)-chains studied by Chung et al. (9) had been pepsin digested. Pepsin digestion is known to remove the nonhelical teleopeptide from the C-terminal peptide $\alpha 1$ (III) CB9 (9). When lung cell culture $\alpha 1$ (III)-chains are subjected to limited pepsin digestion, the $\alpha 1$ (III)CB9 peptide elutes earlier from CM-cellulose (compare Fig. 5 to Fig. 3C). Thus, the longer C-terminal teleopeptide on the intact $\alpha 1$ (III)CB9 peptide probably causes it to be eluted from CM-cellulose at higher salt concentrations.

Studies utilizing the established fetal human lung fibroblast line WI-38 clearly show that lung fibroblasts do synthesize type I and type III collagen. The newborn rabbit lung cells grown in culture had a distinctly fibroblastic appearance at the time collagen synthesis was investigated, and thus, it is probable that fibroblasts contribute to at least part of the type I and type III collagen synthesized by rabbit lung cells as well. Recent studies in our laboratory have demonstrated that cat lung fibroblasts isolated from single cell clones do synthesize type I and III collagen.

The relative propertion of peaks II and III present in culture medium suggests that newborn rabbit lung cells were more active in synthesis of type III collagen than WI-38 human lung fibroblasts. The WI-38 lung fibroblasts were in much higher passage number than the rabbit lung cells, which could explain this finding, although other factors, such as synthesis of $\alpha 1$ (III) by other cell types in the rabbit lung cultures, species dif- 
ferences, differences between fetal and newborn fibroblasts, or preferential processing of proa1(III) to insoluble $\alpha 1$ (III) by WI-38 fibroblasts could also be responsible. Techniques for quantitating synthesis rates of each collagen type by cells in culture, including single cell clones, are being developed and should help resolve this issue. The finding of a single cell type directing the synthesis of three different collagen chains offers an interesting model for the study of the control of gene expression by lung cells in vitro.

The function of type III collagen in any tissue is not known. Type III collagen has been identified only in association with type I collagen; it comprises a significant percentage of the total collagen of several vascular structures and fetal but not adult skin $(8,10,12)$. Its isolation so far only from tissues which support an epithelium or endothelium has also been discussed (10). The identification of $\alpha 1$ (III) synthesized by lung cells and the characterization of its $\mathrm{CNBr}$ peptides will now allow further studies to determine its localization to specific structures within lung, determination of all cell types responsible for its synthesis, and investigation of its role in development, structure, mechanical properties, and diseases of lung.

Collagenous proteins of molecular weight 110-120,000 ( $p \alpha$-chains) of $130-140,000$ daltons (pro $\alpha$-chains) with terminal extensions susceptible to limited pepsin digestion have been identified for both type I and type III collagen synthesized by lung cells. Whether p $\alpha$-chains represent a necessary intermediate in the conversion of procollagen to collagen has not been conclusively established. However, the finding of similar higher molecular weight precursors to $\alpha 1$ (I), $\alpha 2$, and $\alpha 1$ (III) suggests that conversion of both type I and type III collagen in lung may take place by mechanisms analogous to those in other tissues.

A major problem in studying lung collagen has been the difficulty in extracting intact collagen chains from lung. Less than $10 \%$ of the total collagen of fetal lung can be extracted intact (2), while less than $1 \%$ of the total collagen of adult lung can be extracted without the use of proteolytic enzymes or detergents (21). It has thus been necessary to analyze the heterogeneity of lung collagen through the use of protein synthesis techniques rather than by methods specifically developed for collagen chemistry. Lung explant techniques enabled us to assign the synthesis of types I and II collagen to specific lung structures. We have not as yet been able to assign the synthesis of type III collagen to specific lung structures because of the complexity of lung collagen heterogeneity and the insolubility of type III collagen in lung explants. The adaptation of less complex cell culture techniques has allowed the mapping of lung type III CNBr peptides and assigned at least some of the synthesis of types I and III collagen to the lung fibroblast.

Further use of tissue culture methods similar to those described here should give additional information on lung collagen heterogeneity. With appropriate cell separation and cloning techniques, it should be possible to identify all lung cell types responsible for collagen synthesis and determine the type of collagen synthesized by each cell. For example, we are currently investigating a cell line of epithelial origin derived from lung which actively synthesizes collagen. This, or similar epithelial cell lines may synthesize $\alpha 1$ (IV)-chains, and thus be responsible for the production of lung basement membrane collagen, analogous to the synthesis of $\alpha 1$ (IV) by chick lens epithelial cells (22).

Complete understanding of heterogeneity of lung collagen and identification of all cell types responsible for the synthesis of collagen should provide considerable insight into the role of collagen in lung development and structure. In addition, by determining the type of collagen produced and the cell type responsible, it may be possible to classify the broad group of fibrotic lung disorders on this basis. Such a classification could allow identification of possible etiologic factors in individual cases. In addition, by determining rates of collagen synthesis of specific types of collagen (6) on lung tissue obtained by biopsy, the necessity or effectiveness of therapy could be measured directly

\section{ACKNOWLEDGMENTS}

The authors would like to thank S. McConnell-Breul, J. Collins, G. Martin, J. Lichtenstein, P. Byers, E. Epstein, and E. Miller for helpful discussions and Mrs. Kirsten Cook for preparation of the manuscript.

\section{REFERENCES}

1. Hance, A. J., and R. G. Crystal. 1976. Collagen. In The Biochemical Basis of Pulmonary Function. R. G. Crystal, editor. Marcel Dekker, New York. 1st edition. In press.

2. Bradley, K. H., S. D. McConnell, and R. G. Crystal. 1974. Lung collagen composition and synthesis. Characterization and changes with age. J. Biol. Chem. 249: 2674-2683.

3. Pierce, J. A., and J. B. Hocott. 1960. Studies on collagen and elastin content of the human lung. J. Clin. Invest. $39:$ : 8-14.

4. Johnson, J. R., and F. A. Andrews. 1970. Lung scleroproteins in age and emphysema. Chest. 57: 239-244.

5. Boucek, R. J., N. L. Noble, and A. Marks. 1961. Age and fibrous proteins of the human lung. Gerontologia. 5: $150-157$.

6. Bradley, K., S. McConnell-Breul, and R. G. Crystal. 1975. Collagen in the human lung. Quantitation of rates of synthesis and partial characterization of composition. J. Clin. Invest. 55: 543-550.

7. Bradley, K., S. McConnell-Breul, and R. G. Crystal. 1974. Lung collagen heterogeneity. Proc. Natl. Acad. Sci. U. S. A. 71 : 2828-2832. 
8. Chung, E., and E. J. Miller. 1974. Collagen polymorphism: characterization of molecules with the chain composition $\left[\alpha 1(\text { III) }]_{3}\right.$ in . human tissues. Science (Wash. D. C.). 183 : 1200-1201.

9. Chung, E., E. M. Keele, and E. J. Miller. 1974. Isolation and characterization of the cyanogen bromide peptides from the $\alpha 1$ (III) chain of human collagen. Biochemistry. 1.3 : 3459-3464.

10. Epstein, E. H., Jr. 1974. [ $\alpha 1$ (III) ] 3 human skin collagen. Release by pepsin digestion and preponderance in fetal life. J. Biol. Chem. 249: 3225-3231.

11. Volpin, D., and A. Veis. 1973. Cyanogen bromide peptides from insoluble skin and dentin bovine collagens. Biochemistry. 12 : 1452-1464.

12. Trelstad, R. L. 1974. Human aorta collagens: evidence for three distinct species. Biochem. Biophys. Res. Commun. 57 : 717-725.

13. Epstein, E., Jr. 1974. Isolation of $[\alpha 1 \text { (III) }]_{3}$ collagen from pepsin digests of human skin. Clin. Res. 22: 327A. (Abstr.)

14. Kefalides, N. A., and B. Denduchis. 1969. Structural components of epithelial and endothelial basement membranes. Biochemistry. 8: 4613-4621.

15. Lichtenstein, J. R., P. H. Byers, B. D. Smith, and G. R. Martin. 1975. Identification of the collagenous pro- teins synthesized by cultured cells from human skin. Biochemistry. 14: 1589-1594.

16. Church, R. L., M. L. Tanzer, and C. M. Lapiere. 1973. Identification of two distinct species of procollagen synthesized by a clonal line of calf dermatosparactic cells. Nat. New Biol. 244 : 188-190.

17. Smith, B. D., P. H. Byers, and G. R. Martin. 1972. Production of procollagen by human fibroblasts in culture. Proc. Natl. Acad. Sci. U. S. A. 69: 3260-3262.

18. Goldberg, B., and C. J. Sherr. 1973. Secretion and extracellular processing of procollagen by cultured human fibroblasts. Proc. Natl. Acad. Sci. U. S. A. 70: 361-365.

19. Goldberg, B., E. H. Epstein, Jr., and C. J. Sherr. 1972. Precursors of collagen secreted by cultured human fibroblasts. Proc. Natl. Acad. Sci. U. S. A. 69: 3655-3659.

20. Bornstein, P. 1974. The biosynthesis of collagen. Ann. Rev. Biochem. 43: 567-603.

21. Crystal, R. G. 1974. Lung collagen: definition, diversity and development. Fed. Proc. 33: 2248-2255.

22. Grant, M. E., N. A. Kefalides, and D. J. Prockop. 1972. The biosynthesis of basement membrane collagen in embryonic chick lens. I. Delay between the synthesis of polypeptide chains and the secretion of collagen by matrix-free cells. J. Biol. Chem. 247 : 3539-3544. 